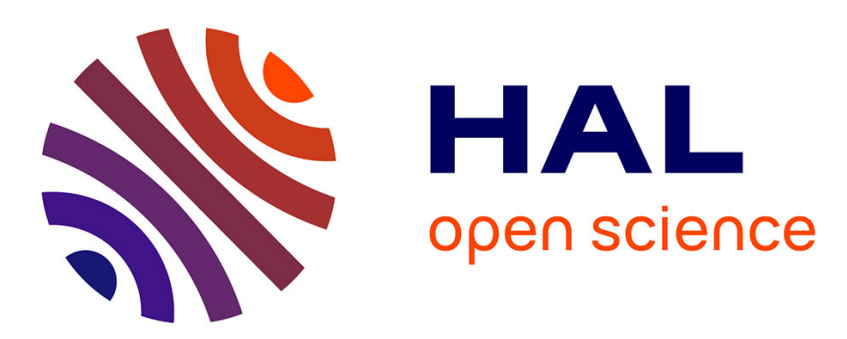

\title{
Electronic device to remove effects of field emission instability on display in scanning electron microscopy
}

P Morin, C. Rolland, M. Pitaval, E. Vicario

\section{To cite this version:}

P Morin, C. Rolland, M. Pitaval, E. Vicario. Electronic device to remove effects of field emission instability on display in scanning electron microscopy. Revue de Physique Appliquée, 1978, 13 (1), pp.39-41. 10.1051/rphysap:0197800130103900 . jpa-00244419

\section{HAL Id: jpa-00244419 https://hal.science/jpa-00244419}

Submitted on 1 Jan 1978

HAL is a multi-disciplinary open access archive for the deposit and dissemination of scientific research documents, whether they are published or not. The documents may come from teaching and research institutions in France or abroad, or from public or private research centers.
L'archive ouverte pluridisciplinaire HAL, est destinée au dépôt et à la diffusion de documents scientifiques de niveau recherche, publiés ou non, émanant des établissements d'enseignement et de recherche français ou étrangers, des laboratoires publics ou privés. 
Classification

Physics Abstracts

$79.20-79.70-07.80$

\title{
ELECTRONIC DEVICE TO REMOVE EFFECTS OF FIELD EMISSION INSTABILITY ON DISPLAY IN SCANNING ELECTRON MICROSCOPY
}

\author{
P. MORIN, C. ROLLAND, M. PITAVAL and E. VICARIO
}

Département de Physique des Matériaux

43, boulevard du 11-novembre-1948, 69621 Villeurbanne, France

(Reçu le 11 mai 1977, révisé le 14 septembre 1977, accepté le 21 septembre 1977)

\begin{abstract}
Résumé. - De nombreuses observations en microscopie électronique à balayage nécessitent une intensité de faisceau très stable. Avec un canon à émission de champ, il n'est pas possible de stabiliser l'intensité du faisceau en modifiant la polarisation des électrodes sans changer sa focalisation comme il est possible de le faire avec un canon thermoélectronique. Nous avons adapté un dispositif électronique qui permet de supprimer totalement l'influence des fluctuations du faisceau sur le signal vidéo.
\end{abstract}

\begin{abstract}
Many observations in scanning electron microscopy need a very stable beam current. With a field emission gun, the beam current cannot be stabilized by modifying the electrodes bias without defocusing, as it can be done with thermoionic guns. An electronic device has been adapted which permits to remove almost all influence of beam fluctuations on the video signal.
\end{abstract}

1. Introduction. - A field emission electron gun was made and adapted onto the objective lens and the modified specimen chamber of a standard scanning electron microscope (Cambridge Stereoscan MkIIa). The gun description and first results obtained are published elsewhere [1]. The aim of this paper is to describe the stabilizing system we have designed to prevent image troubles due to fluctuations of the beam current.

We use a (111) oriented tungsten emitting tip builtup under an applied electric field at $1700 \mathrm{~K}$, then heated to $1200 \mathrm{~K}$ during emission [2]. Build-up process increases beam current available, and $1200 \mathrm{~K}$ heating avoids drift of the emission current for periods longer than 4 hours. Emission is stable enough to observe specimens which need little expansion of contrast such as twins in stainless steel (Fig. 1) observed by scanning transmission mode (STEM). As black level of the video signal is increased, beam intensity fluctuations appear on the pictures as variations of the scanning lines intensity. Figure 2, showing a network of dislocations on a molybdenite sample by STEM mode, was obtained using contrast expansion. Finally, fine details giving signal variations as low as beam fluctuations cannot be observed.

2. Principle. - One method, as for thermoionic guns is to stabilize the emission by controlling the extracting voltage applied to the tip, driven by the beam intensity. This is inconvenient since the optical

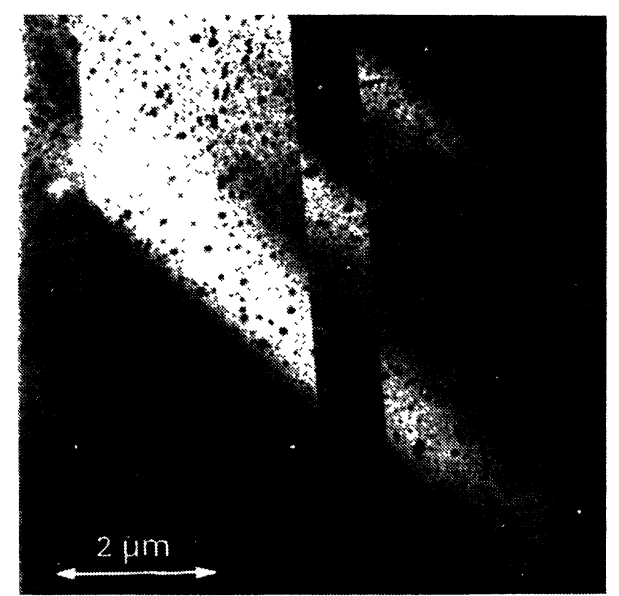

FIG. 1. - STEM image of twins in a stainless steel.

properties of the gun vary with this voltage for a given acceleration, leading to a defocus in the final spot. Therefore, a gun with four electrodes is needed resulting in reduced gun performance [3].

Other methods are based on the mixing of two signals from the sample :

- for thin specimen, Crewe [4] uses elastically and inelastically scattered electrons;

- for Auger analysis, Todd et al. [5] use Auger signal and secondary electrons signal. 


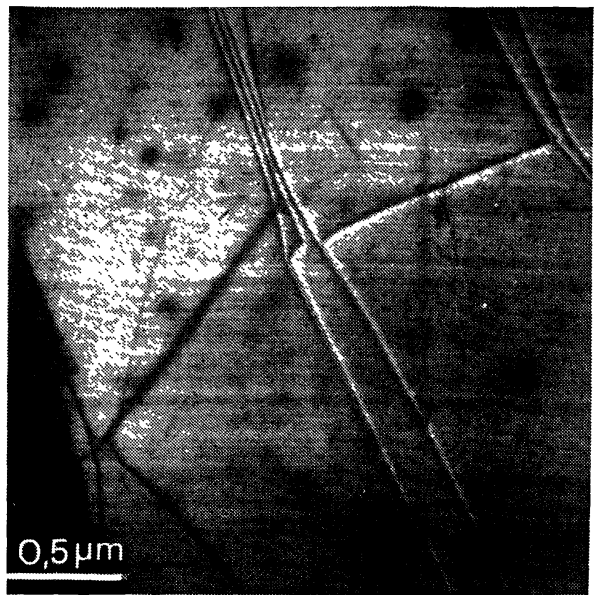

FIG. 2. - STEM image of dislocations in a molybdenite sample

We propose a method efficient for every case : to divide the video signal $A \alpha I_{0}$ ( $A$ : amplification coefficient, $\alpha:$ response of the object to the beam) by a signal $B I_{0}$, proportionnal to the beam current $I_{0}$. The signal obtained $\frac{A \alpha}{B}$, where $A$ and $B$ are constants, depends only on the object.

Expansion of the image contrast is obtained by increasing the gain of the photomultiplier; at the same time, a d. c. voltage has to be subtracted from the video signal at the first stage of the preamplifier to avoid saturation. When divided by $B I_{0}$, the signal again becomes dependant on $I_{0}$. So, instead of a d. c. voltage, we subtract a $C I_{0}$ signal proportional to the beam current. Dividing by $B I_{0}$ leads to a $\frac{A \alpha-C}{B}$ signal which is independant of $I_{0}$ and whose contrast is governed by $C$.

3. Implementation. - To obtain a signal proportional to the beam current, the whole emitted current from the tip cannot be used : fluctuations are not correlated to each other. We use the part of the beam stopped by the final aperture sides between the pole pieces of the objective lens. As this aperture is not at cross-over position, it is reached by electrons coming from the same tip are a as the beam on the specimen. The current reaching the aperture side is low $\left(10^{-11}\right.$ to $10^{-10} \mathrm{~A}$ ) ; we use a scintillator-photomultiplier assembly which detects electrons backscattered by the aperture, thus taking advantage of the low-noise and the large bandwith of the photomultiplier amplification.

A scheme of the detection assembly is shown in figure 3. The standard aperture holder has been changed, but the new version keeps the aperture centring, and the column isolating valve unmodified. The light-pipe (1) and scintillator (2) assembly is held by the aperture holder (3) with the scintillator close to the aperture. For the gun accelerating voltages used (down to $10 \mathrm{kV}$ ), the scintillator does not need accelera-

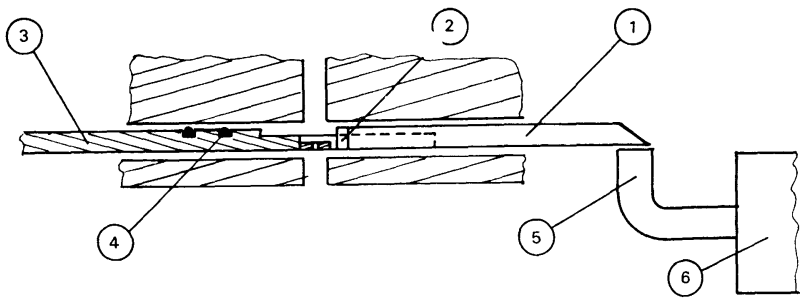

FIG. 3. - Detection of the electrons backscattered by the final aperture : (1) light-pipe, (2) scintillator, (3) aperture holder,

(4) isolating valve, (5) light-pipe, (6) photomultiplier.

tion of backscattered electrons. When the isolating valve (4) is opened, the bevelled end of the light-pipe reflects scintillation light towards the light-pipe (5) which leads light to the photomultiplier (6). To avoid charging of the perspex light-pipe, it is aluminium coated for half its length.

The schematic diagram of the electronic circuits is show in figure 4 . By using a classical divider with a $1 \mathrm{MHz}$ bandwidth (2) the signal from the specimen, through the standard preamplifier (1) is divided by the preamplifier (3) output signal provided by electrons backscattered onto the aperture. The preamplifier (3),

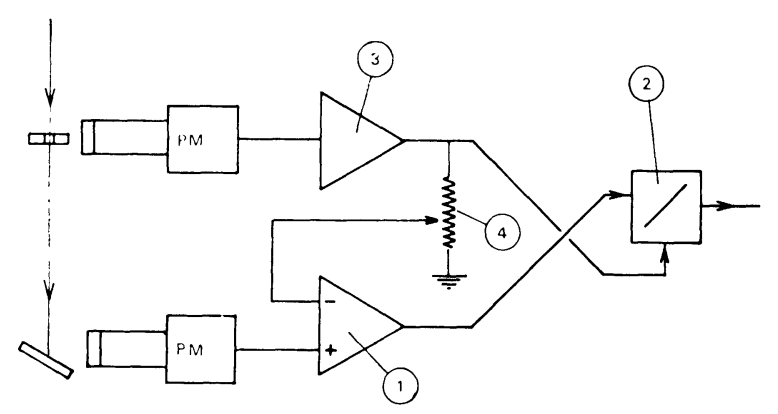

Fig. 4. - Scheme of the electronic device : (1) standard preamplifier, (2) divider, (3) preamplifier, (4) potentiometer.

an operationnal amplifier followed by a power transistor, has a $10 \mathrm{kHz}$ limited bandwidth : in the case of a wider band, noise is introduced, and in the case of a more narrow band, fluctuations do not disappear completely. This chosen bandwidth is convenient for all scanning frame rates.

The potentiometer (4) adjusts the amplitude of the subtracted signal for black level. The gain of the photomultiplier is adjusted by observing the corrected video signal with an oscilloscope.

4. Results. - Figure $5 a$ was obtained on a silver grid test sample with expanded contrast and a high emission current. Figure $5 b$ shows the efficiency of the corrections ; it is recorded with the same contrast and emission current conditions.

With a detection assembly adapted to the environment of the defining aperture, this system can be used in conjunction with any reflection or transmission scanning electron microscopy using a field emission gun. 


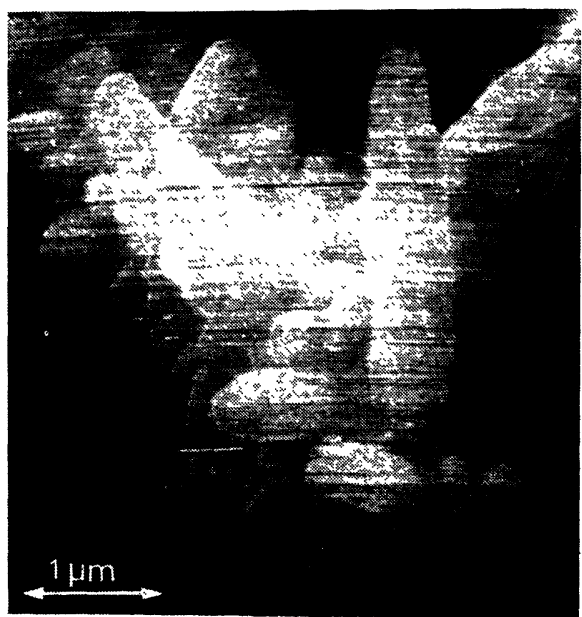

(a)

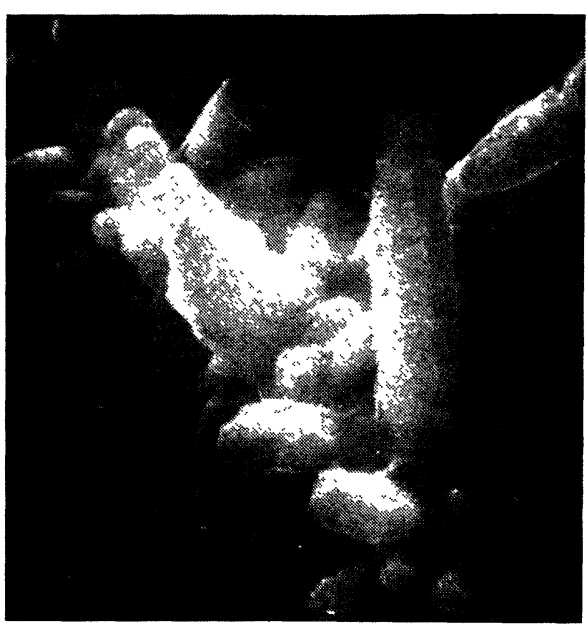

(b)

Fig. 5. - Silver grid test sample : $a$ ) without correction, $b$ ) with correction.

\section{References}

[1] Pitaval, M., Morin, P., Baudry, J., Fontaine, G., Meeting of the electron Microscopy and Analysis Group of the Institute of Physics Bristol, Septembre 1975.

[2] Ranc, S., Pitaval, M., Fontaine, G., Surf. Sci. 57 (1976) 667.
[3] Cleaver, J. R. A., Int. J. Electron. 4 (1975) 531.

[4] Crewe, A. V., Q. Rev. Biophys. 1 (1970) 137.

[5] Todd, G., Poppa, H., Moorhead, D., Bales, M., J. Vac. Sci. Technol. 4 (1975) 953. 